\title{
Lamps and Wavelengths of Mercury 198
}

\author{
By William F. Meggers and F. Oliver Westfall
}

\begin{abstract}
The production and extraction of artificial ${ }_{80}^{198} \mathrm{Hg}$ from ${ }_{79}^{197} \mathrm{Au}$ bombarded by neutrons is described, and the procedure in making electrodeless lamps with ${ }_{80}^{198} \mathrm{Hg}$ is given in detail. These lamps are excited by high-frequency radio waves; they emit the mercury spectrum entirely free from isotope shifts and hyperfine structures that characterize natural mercury. Fabry-Perot interferometers and a prism spectrograph were employed for measuring, relative to $\mathrm{Cd} 6438.4696$ angstroms, the wavelengths of the stronger lines in the visible spectrum of ${ }_{80}^{198} \mathrm{Hg}$. Preliminary values for ${ }_{80}^{198} \mathrm{Hg}$ radiations in normal air are reported as 5790.6627, 5769.5984, 5460.7532, 4358.3377, 4077.8383, and 4046.5717 angstroms, with probable errors not exceeding \pm 0.0001 angstrom.
\end{abstract}

\section{Introduction}

In a paper entitled "On the feasibility of establishing a light wave as the ultimate standard of length", Michelson and Morley [1] ${ }^{1}$ in 1889 described the method later employed in measuring the meter and reported the first interferometer values of wavelengths for one sodium line, one lithium line, and three mercury lines. They also stated that "the brilliant green (mercury) line gives beautifully clear circles even with a difference of path of half a million waves, so that in all probability this will be the wave to be used as the ultimate standard of length". However, in 1892 Michelson [2] discovered that many spectral lines are complex and that "the green mercury line is one of the most complex yet examined". This observation disqualified radiations from natural mercury as precision standards for more than half a century, during which time the causes and cures of spectral line complexities were sought and found. The mass spectrometer disclosed [3] that natural mercury is a mixture of seven isotopes with mass numbers 196, 198, 199, 200, 201, 202, 204 , and the interferometer resolved the components of complex lines so that they could be quantitatively explained [4] as resulting in part from isotope shifts and in part from hyperfine structure due to nuclear spins of $1 / 2$ and $3 / 2$ units for

\footnotetext{
${ }_{1}^{1}$ Figures in brackets indicate the literature references at the end of this paper.
}

isotopes 199 and 201, respectively. It was obvious in 1931 that single sharp lines could be obtained from any even-mass isotope of mercury if such an isotope could be produced in sufficient quantity and purity for spectroscopic light sources. The latter requirements ruled out, at least temporarily, any physical methods of separating the isotopes of natural mercury. Fortunately another solution was found in transmutation.

Although nuclear reactions with certain elementary particles were known to transmute some elements into others, such experiments yielded only infinitesimal amounts that could not be seen or weighed. Thus, in 1934 Fermi, et al. [5] used a mixture of beryllium powder and radon as a neutron source to transmute gold into mercury, but it was wholly impracticable to make tangible amounts of mercury this way. In 1940 Alvarez boldly suggested that neutrons obtained from cyclotron operations might transmute sufficient gold into mercury to be detected spectroscopically. This experiment was successful and demonstrated that the green line of artificial mercury was devoid of complex structure [6, 7]. Attempts to produce ponderable amounts of ${ }_{80}^{198} \mathrm{Hg}$, required for many durable lamps, were frustrated until a more powerful source of neutrons became available. The chain-reacting uranium piles proved ideal for this purpose, and with the cooperation of the United States Atomic Energy Commission, sufficient artificial ${ }_{80}^{198} \mathrm{Hg}$ has been made since 1945 to provide 
several hundred satisfactory spectroscopic light sources. Now that the isotopic curse has been lifted from mercury and ${ }_{80}^{198} \mathrm{Hg}$ has become available in abundance, there are good reasons for believing "that in all probability the brilliant green (mercury) line will be the wave to be used as the ultimate standard of length" $[1,8,9,10]$. It is the purpose of this paper to describe the preparation and operation of ${ }_{80}^{198} \mathrm{Hg}$ lamps and to report some preliminary results of measurements on wavelengths emitted by these lamps.

\section{Production and Extraction of Artificial ${ }_{80}^{198} \mathrm{Hg}$}

Gold of high purity (999.9 fine) in the form of foil or chips was first placed in a fused quartz well attached by means of a graded seal to Pyrex tubing leading to a vacuum pump through a trap immersed in liquid air. The enclosed gold was surrounded by an electrically heated furnace, maintained at $800^{\circ} \mathrm{C}$ for about $20 \mathrm{hr}$ to remove possible contamination by natural mercury. No mercury contamination could be detected in gold foil purchased from the New York Assay Office.

This mercury-free gold was then submitted to the U. S. Atomic Energy Commission for irradiation with neutrons in a chain-reacting pile. The production of artificial ${ }_{80}^{198} \mathrm{Hg}$ from ${ }_{79}^{197} \mathrm{Au}$ occurs when neutrons that attach themselves to nuclei of gold atoms produce a highly radioactive isotope of ${ }_{79}^{198} \mathrm{Au}$, which decays (half.life 2.7 days) by $\beta$ emission to become stable ${ }_{80}^{198} \mathrm{Hg}$; symbolically:

$$
{ }_{79}^{197} \mathrm{Au}^{0}+1 n^{0} \rightarrow{ }_{79}^{198} \mathrm{Au}^{0} \rightarrow{ }_{80}^{198} \mathrm{Hg}^{0}+\beta^{-1} .
$$

After a period for neutron bombardment and another for radioactive decay, the gold was returned to our laboratory, where it was treated for the removal of artificial ${ }_{80}^{198} \mathrm{Hg}$ in the same manner as formerly for extraction of natural $\mathrm{Hg}$ contamination. Mercury that distilled from the heated gold first condensed in tiny droplets on cooler glass walls above the furnace from whence it was driven to the liquid-air trap by flaming with a gasair torch. To be certain that all the artificial mercury had been extracted, this procedure was continued several hours after the last visible traces of condensation could be detected above the furnace.

The yield and purity of ${ }_{80}^{198} \mathrm{Hg}$ are both under control; the former depends on the quantity of gold and the time of exposure to a given neutronflux density, the latter is inversely proportional to the flux density. Mass-spectrometer analyses [11] of artificial ${ }_{80}^{198} \mathrm{Hg}$ invariably show some contamination by ${ }_{80}^{199} \mathrm{Hg}$, suggesting that a fraction of the ${ }_{79}^{198} \mathrm{Au}$ atoms, before decaying to ${ }_{80}^{198} \mathrm{Hg}$, accrete another neutron to become ${ }_{79}^{199} \mathrm{Au}$, which then decays to ${ }_{80}^{199} \mathrm{Hg}$. Kessler [12] has demonstrated that such ${ }_{80}^{199} \mathrm{Hg}$ contamination in impure ${ }_{80}^{198} \mathrm{Hg}$ can be determined from the intensity of a forbidden line. A purity of 99.6 percent, or greater, can be guaranteed by choosing a low neutronflux density, as lower yield can be compensated either by more gold or by longer exposure.

For many years it seemed hopeless to effect a large-scale production of pure isotopes by electromagnetic separation, but this outlook was changed in 1945 when the colossal calutrons constructed for separating uranium isotopes were applied to the enrichment of stable isotopes. Keim [13] reported recently that ${ }_{80}^{202} \mathrm{Hg}$ has thus been enriched from 11 to 98 percent, ${ }_{80}^{204} \mathrm{Hg}$ from 7 to $>92$ percent. Whether or not these electromagnetically separated natural isotopes will be produced in sufficient quantity and purity to compete with artificial ${ }_{80}^{198} \mathrm{Hg}$ remains to be seen. The production and extraction of high-purity ${ }_{80}^{198} \mathrm{Hg}$ from pure ${ }_{79}^{197} \mathrm{Au}$ is such a simple and sure procedure that it can hardly be surpassed.

\section{Manufacture of ${ }_{80}^{198} \mathrm{Hg}$ Lamps}

The first ${ }_{80}^{198} \mathrm{Hg}$ lamp made at this Bureau in 1946 was an electrodeless Pyrex-glass tube (5-mm bore, $10-\mathrm{cm}$ length) containing an invisible quantity of ${ }_{80}^{198} \mathrm{Hg}$ and some argon gas; it was excited with a $100-\mathrm{Mc}$ oscillator constructed by Wiens [7], and it emitted intense structureless lines of the mercury spectrum for about $50 \mathrm{hr}$ before failing on account of clean-up [9]. Attempts to rejuvenate this lamp by heating were frustrated by the liberation of adsorbed gases whose spectra suppressed that of mercury. This experience suggested the use of fused quartz or Vycor glass (96\% silica), which withstand higher temperatures than Pyrex and are therefore more easily out-gassed before ${ }_{80}^{198} \mathrm{Hg}$ is inserted.

In 1947 about $60 \mathrm{mg}$ of ${ }_{80}^{198} \mathrm{Hg}$ of 99.9 percent purity [11] were obtained from neutron-irradiated gold, and four experimental lamps were made 

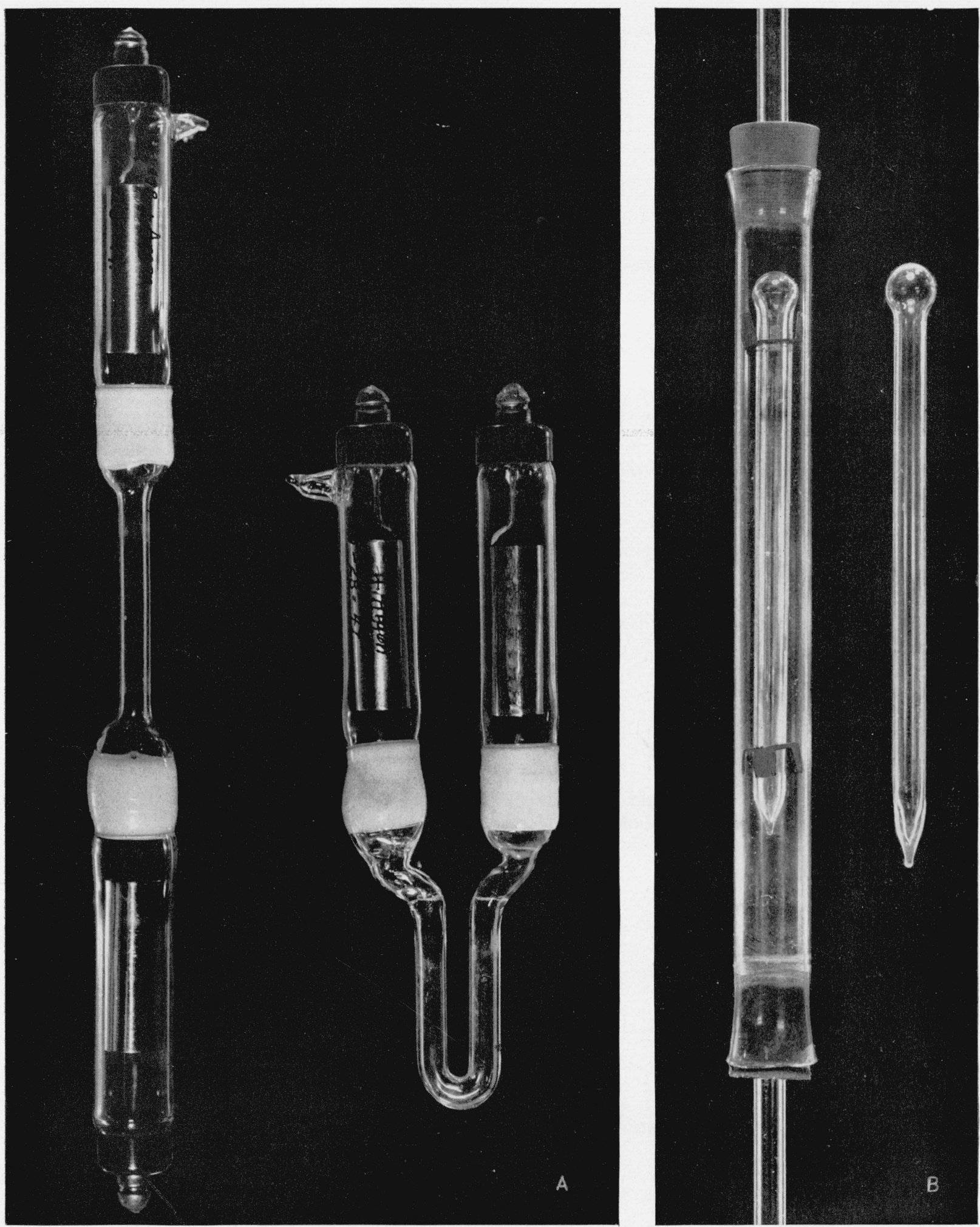

Figure 1.

A, Geissler-type lamps containing ${ }_{80}^{198} \mathrm{Hg}$. Straight lamp is $25 \mathrm{~cm}$ long. B, Electrodeless lamps containing ${ }_{80}^{198} \mathrm{Hg}$, one in water jacket. Length of lamp about $12 \mathrm{~cm}$. 
with $5 \mathrm{mg}$ of ${ }_{80}^{198} \mathrm{Hg}$ and 5 -mm $(\mathrm{Hg})$ pressure of pure argon in each. Two of these lamps were Geissler type of Vycor glass with internal electrodes of molybdenum, figure $1, \mathrm{~A}$, and two were electrodeless type, one of Vycor and one of fused quartz, figure 1, B. We are indebted to N. C. Beese of the Research Division, Westinghouse Lamp Division, Bloomfield, N. J., for making the Geissler lamps and fused-quartz lamp, and for advice on their proper preparation.

The first experiments designed to measure wavelengths emitted by these lamps soon led to the abandonment of the Geissler-type on account of lower intensity and inferior sharpness of lines when compared with electrodeless lamps. The latter are the last word in simplicity and serviceability; they simplify manufacture by eliminating sealed-in wires, graded seals, and internal electrodes, thus facilitating exhausting and outgassing. In service they avoid high voltage, sparking, sputtering, and all other defects of Geissler tubes. Because these electrodeless lamps have been found to be highly satisfactory, their preparation will be described in some detail.

The essentials for making ${ }_{80}^{198} \mathrm{Hg}$ lamps are, in addition to ${ }_{80}^{198} \mathrm{Hg}$, clean glass tubing, vacuum pumps, a bottle of pure argon gas, a low-range gas pressure indicator, and a gas-oxygen hand torch. Either clear fused quartz or Vycor glass is recommended because of high melting point and transparency to ultraviolet. Unless the extreme ultraviolet is desired, fused quartz should be avoided because its high transparency to $\mathrm{Hg} 1849 \mathrm{~A}$ radiation permits the formation of obnoxious ozone in the laboratory. Vycor is preferred because it transmits practically all $\mathrm{Hg}$ radiations except that forming ozone. The glass is first cleaned with hot chromic acid and rinsed with distilled water.

To eliminate the hazard of contamination with natural mercury, the use of mercury pumps and manometers should be avoided. Evacuation was effected with an oil forepump and oil-condensation pump; and for measuring the pressure of argon gas, either a calibrated dark space in an attached Geissler tube or a mechanical pressure gage was employed.

The procedure in making an electrodeless $\mathrm{Hg}$ lamp may be outlined with the aid of figure 2 . Sections $A$ and $B$ are cleaned Vycor glass (5-mm bore). Section $A$ is the lamp blank with constriction, $a$, and sealed upper end blown bulbous

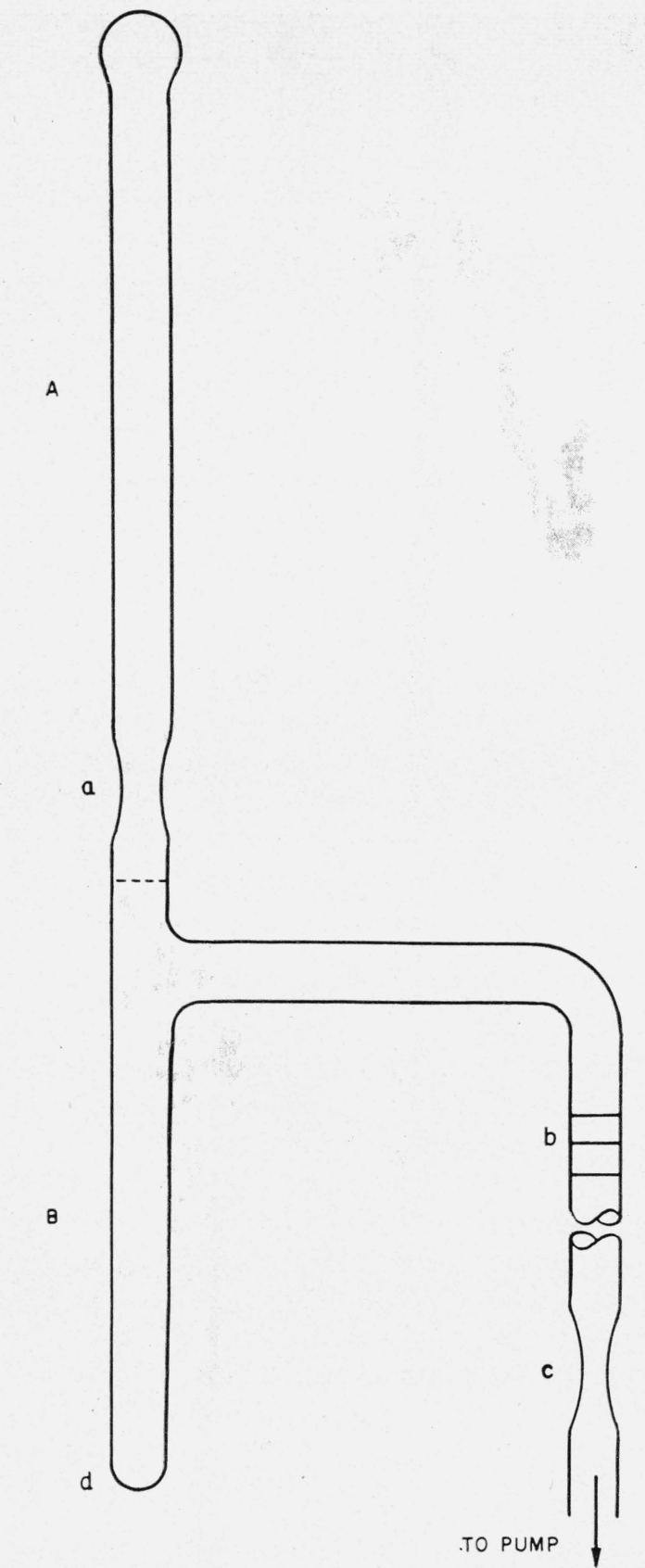

Figure 2. Manufacture of electrodeless mercury lamp. $A=$ lamp blank. $B=$ mercury well.

so that the lamp may be viewed end-on if desired. Section $B$ is the mercury well with a side tube provided with a Vycor-Pyrex joint, $b$, and constriction, $c$. A broken thermometer tube modified on the principle of the medicine dropper serves for withdrawing from the supply a measured amount of ${ }_{80}^{198} \mathrm{Hg}$ and depositing it as a droplet, $d$, at the bottom of section $B$. This section is then 
sealed to the pump (and argon flask), and section $A$ is sealed onto section $B$. In making these seals, and in subsequent heating for out-gassing, accidental overheating of the droplet, $d$, and consequent loss of ${ }_{80}^{198} \mathrm{Hg}$, is avoided by wrapping the lower half of section $B$ with wet asbestos paper. During evacuation section $A$ and the uncovered portion of section $B$ are heated with a gas-oxygen torch until a nonconducting vacuum has been attained. After a measured pressure of pure argon gas has been admitted, the assembly $A B$ is sealed off at constriction, $c$, and inverted to roll or tap the droplet of mercury into the bulbous end of section $A$. Finally, section $A$ is sealed off at constriction, $a$, thus completing an electrodeless lamp containing pure mercury and argon gas. The presence of argon gas retards the clean-up of mercury, increases the intensity of the mercury spectrum, and facilitates operation of the lamp when immersed in cold, circulating water.

\section{Mercury Clean-Up in Electrodeless Lamps}

Experience with these lamps since 1947, and the limited supply of ${ }_{80}^{198} \mathrm{Hg}$, persuaded us to reduce the mercury content of future lamps to $3 \mathrm{mg}$ or less. It was recognized in 1946 that gradual clean-up of mercury would limit the life of a lamp, but it was not known then that such clean-up could be retarded or corrected. Experiments were conceived and conducted to determine the minimum mercury required for a long-lived lamp. Several lamps, each containing $1 \mathrm{mg}$ of natural mercury and $5 \mathrm{~mm}(\mathrm{Hg})$ pressure of argon, were prepared and life-tested at equal brightness on three different high-frequency exciter units emitting 30,60 , and $90 \mathrm{Mc}$, respectively. These units were constructed by Albert Weiss of this Bureau. We were surprised to find that, with $30 \mathrm{Mc}, 1 \mathrm{mg}$ of $\mathrm{Hg}$ was cleaned up in about $10 \mathrm{hr}$, with $60 \mathrm{Mc}$ in $55 \mathrm{hr}$, and with $90 \mathrm{Mc}$ in $2,630 \mathrm{hr}$. This experience prompted us to experiment with still higher frequencies. A lamp excited with $370 \mathrm{Mc}$ for several months exhibited no trace of darkening or clean-up despite operation at a higher level of brightness. Jacobsen and Harrison [14] have recently reported high intensity and undetectable clean-up when a ${ }_{80}^{198} \mathrm{Hg}$ lamp was excited with $3,000 \mathrm{Mc}$ generated by a magnetron.

The clean-up is manifested by gradual darken- ing of the glass near the terminals of the highfrequency exciter until black bands are formed on the inner wall of the lamp. If the lamp is held in spring clips no darkening occurs under the clips, but only outside their boundaries. Identical effects have been observed with Pyrex, Vycor, and fused silica; blackening continues until all the enclosed mercury has penetrated the glass, whereupon the mercury spectrum vanishes and pure argon remains. Preliminary experiments with various pressures of argon indicate a marked dependence of $\mathrm{Hg}$ clean-up upon gas pressure. Two lamps, each containing $1 \mathrm{mg}$ of $\mathrm{Hg}$, were filled with 5 and $15 \mathrm{~mm}$ of argon, respectively, and operated at constant intensity with $30 \mathrm{Mc}$ until the $\mathrm{Hg}$ spectrum vanished; the first lamp glowed for $45 \mathrm{hr}$ and the second for $365 \mathrm{hr}$. These experiments, indicating that the rate of $\mathrm{Hg}$ clean-up in ultrahigh-frequency discharges decreases with frequency and with gas pressure, are being continued; they will be reported in more detail later. The mechanism of $\mathrm{Hg}$ clean-up is imperfectly understood, but the following facts are fixed. $\mathrm{Hg}$ clean-up in electrodeless discharge tubes is extremely slow if the oscillatory excitation frequency exceeds $100 \mathrm{Mc}$ and if the foreign gas pressure exceeds $5 \mathrm{~mm}(\mathrm{Hg})$. In any case the clean-up is localized near the edges of the high-frequency terminals, resulting in black bands inside the lamp. This leads finally to extinction of the mercury light. In that event it is only necessary to heat the blackened portions of the lamp in a gasoxygen flame until they glow a dull red. This treatment removes the blackening, recovers visible droplets of mercury, restores the $\mathrm{Hg}$ spectrum, and rejuvenates the lamp without detriment to the Vycor glass. In tests of $\mathrm{Hg}$ clean-up the same lamp has been resurrected several times, thus indicating that even if the clean-up cannot be entirely eliminated, successive rejuvenations guarantee practically infinite life.

\section{Wavelengths Radiated by ${ }_{80}^{198} \mathrm{Hg}$}

Superior spectroscopic light sources are of no value for length measurements until the lengths of several radiated light waves have been measured. Such measurements have been made by comparing the light waves characteristic of ${ }_{80}^{198} \mathrm{Hg}$ with the primary standard of wavelength, $6438.4696 \mathrm{~A}$, provisionally adopted [10] as the 
metric value of the red radiation from Michelson's type of cadmium lamp. For this purpose we employed the method first demonstrated by Buisson and Fabry [15] and used for the past 40 years in making the most precise determinations of relative wavelengths. This method, as is well known, is based on the principle that wavelengths of monochromatic radiations are inversely proportional to the corresponding orders of interference determined from linear measurements of circular fringes produced by the Fabry-Perot interferometer. The only improvements upon the method as originally described consist of simultaneous illumination of the optical system by both light sources, and application of least squares in the reduction of measurements.

In our experiments the mercury lamp was imaged inside the cadmium lamp, and both sources were then focused upon the slit of a prism spectrograph. Both sources and lenses were initially placed on the optical axis of the spectrograph by bisecting the beam emerging from the slit when a bright light was placed at the spectrograph focus. Then the interferometer and the achromatic ring-projection lens were inserted in the beam and adjusted so that the interference fringes were accurately centered and focused on the spectrograph slit. Simultaneous observation of both sources avoids all errors resulting from slight changes in air density or optical adjustments between successive exposures to separate sources. The Michelson-type cadmium lamp was enclosed in a furnace maintained at 300 to $320^{\circ} \mathrm{C}$., and the capillary was viewed end-on. The electrodeless mercury lamp was maintained at a temperature between $10^{\circ}$ and $20^{\circ} \mathrm{C}$, and was always viewed side-on.

The Fabry-Perot interferometer consisted of adjustable etalons holding a pair of crystal quartz plates separated by three invar pins. The plates were coated with evaporated aluminum having reflectance of 80 percent at $6000 \mathrm{~A}$. Invar separators of $3,5,25,40,50,67,90$, or $105 \mathrm{~mm}$ were employed. In order to maintain an approximately constant scale of interference fringes, achromatic lenses of different focal lengths were used with different plate spacers; $25 \mathrm{~cm}$ with 3 or $5 \mathrm{~mm}, 50$ cm with 25,40 , or $50 \mathrm{~mm}, 75 \mathrm{~cm}$ with 67 or 90 $\mathrm{mm}$, and $100 \mathrm{~cm}$ with 90 or $105 \mathrm{~mm}$.

The observations reported in this paper were all made photographically with the aid of a Hilger medium spectrograph with glass prism. Four spectrograms were recorded on each 4 by $10 \mathrm{in}$. plate, but no two plates were made with identical interferometer adjustment-the orders of interference were changed slightly from plate to plate so that different configurations of fringes resulted. Beginning with low orders, associated with 3-mm separation of plates, the wavelengths published for natural mercury were accurate enough to give the correct integral orders of interference for the first approximation to wavelengths characteristic of ${ }_{80}^{198} \mathrm{Hg}$. These approximate values were then successively refined by observing with larger and larger orders.

In general, for any given wavelength the corresponding order of interference at the center of a Fabry-Perot pattern consists of an integer and a fraction. Because the squared values of the ring diameters are a linear function of the ring number, the fractional order is simply obtained by dividing the square of the first-ring diameter by the constant difference between squares. Furthermore, because the entire error in the comparison of wavelengths resides in this determination of fractional orders, it is desirable to reduce it by distributing it among several fringes. Finally, to derive the most probably correct values, the observations should be reduced according to the method of least squares. In all our determinations of ${ }_{80}^{198} \mathrm{Hg}$ wavelengths we have measured for each radiation the diameters of either five or six successive rings. These measurements were made with an interference comparator, designed by $\mathrm{K}$. Burns in 1913, constructed in the Bureau's instrument shop, and illustrated in an earlier paper [16]. At first the diameters of six rings were measured, and fractional orders were calculated by the procedure described and recommended by Meissner [17]. Because this procedure involves an inordinate amount of arithmetic, it was abandoned in favor of the procedure earlier described by Holt and Barrell [18]. The latter reduces to an especially simple form when five fringes are measured and all operations are simple mental arithmetic, except squaring the diameters and finding the final quotient that represents the fractional order sought. The squares were taken from Gauss [19] and the quotient from a calculating machine.

Starting with micrometered values of the plate spacers, the correct integral orders of the green and yellow waves of mercury were uniquely de- 
rived from their coincidence rates and observed fractional orders as explained elsewhere [10]. The yellow pair is happily heuristic for the order of interference because coincidences can recur only at intervals of 275 waves. After the correct orders for three mercury lines had been established, the orders corresponding to other known lines, including that for red radiation from cadmium, were calculated. Finally, the wavelengths of several ${ }_{80}^{198} \mathrm{Hg}$ lines were determined relative to $\mathrm{Cd}$ $6438.4696 \mathrm{~A}$ by taking this times its order and dividing that product by the orders of the several ${ }_{80}^{198} \mathrm{Hg}$ lines. These are the correct relative values only if the observations have been made in standard air (pressure $760 \mathrm{~mm} \mathrm{Hg}$ and temperature $15^{\circ}$ C) and provided that the optical distance between the interferometer surfaces is the same for all wavelengths. Because, in general, neither of these conditions is present, Fabry-Perot wavelength determinations require slight corrections for normal air and for dispersion of phase change upon reflection.

The temperature of the air near the interferometer and the barometric pressure were recorded for each spectrogram, and from these data the appropriate air-density corrections to wavelengths were derived directly from tables published by Meggers and Peters [20]. The largest corrections of this type amounted to $-0.0014 \mathrm{~A}$ for $4046 \mathrm{~A}$. Corrections required on account of dispersion of phase change were deduced from systematic differences obtained for wavelengths measured with small and with large orders of interference $[15,21]$. Such systematic differences observed with $5 \mathrm{~mm}$ and with $90 \mathrm{~mm}$ separations of plates are shown in figure 3. All wavelengths (except 6438 A) measured with these particular plates require a positive correction that is a function of

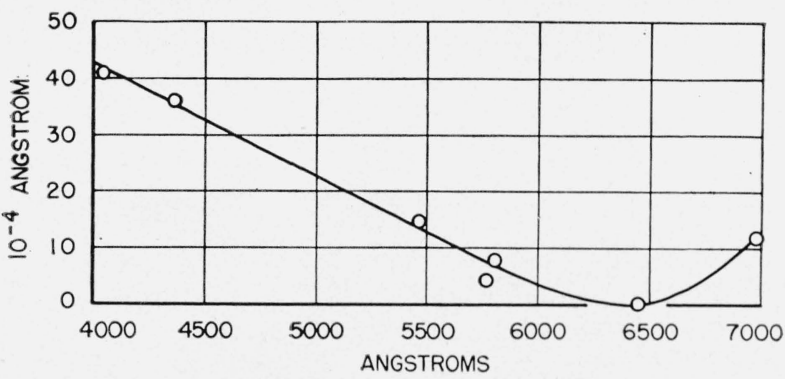

FiguRE 3. Dispersion of phase change on reflectance in aluminum films exhibited as differences in wavelengths from $90-\mathrm{mm}$ and $5-\mathrm{mm}$ separations of plates. wavelength and of order of interference. For 4046 A this correction amounts to $+0.0005 \mathrm{~A}$ when these interferometer plates are separated 40 $\mathrm{mm}$. It is obvious that these required corrections must be evaluated with some care if one desires to express wavelengths correctly within \pm 0.0001 A.

When these wavelength measurements were begun in 1947 a cadmium metal vapor lamp purchased from the Westinghouse Lamp Division [22] was used in lieu of the (lacking) Michelson lamp. The red radiation from this lamp was measured relative to neon standards by Meggers and Humphreys, who reported an increase of wavelength with current [8]. Such a shift in wavelength of the cadmium line emitted by Westinghouse lamps was confirmed by the present experiments after ${ }_{80}^{198} \mathrm{Hg}$ wavelengths were compared with the primary standard emitted by Michelson-type Cd lamps, which we constructed and used during 1948. By measuring the wavelengths of certain ${ }_{80}^{198} \mathrm{Hg}$ lines relative to the red radiation from both types of Cd lamps we arrived at the ratio of 1.00000023 for $\mathrm{Cd}$ (Westinghouse) to $\mathrm{Cd}$ (Michelson) when the former lamp is operated with 3 to 4 amp.

In 1949 we experimented with an "Osram" cadmium vapor lamp made by the General Electric Company of England and were satisfied that the wavelength of its red radiation is practically the same as that from the standard Michelson lamp. After innumerable discouraging experiences with Michelson lamps on account of their smallness, faintness, short life, etc., and after disappointment that the wavelength of cadmium light from Westinghouse lamps is not constant, it was a pleasure to work with the improved cadmium lamp supplied by the General Electric Company of England. Unfortunately, the latter does not conform to construction and operation specifications adopted by the International Committee on Weights and Measures [23] and by the International Astronomical Union [24].

Preliminary results for wavelengths of ${ }_{80}^{198} \mathrm{Hg}$ visible radiations are presented in tables 1 and 2 . Table 1 contains our first results based on Westinghouse cadmium lamps but now corrected to the scale of wavelengths fixed by the Michelson type of cadmium lamp. The results given in table 2 are based on Michelson cadmium lamps and are therefore preferable to those given in table 1 . 
Only results from plate separations of $40 \mathrm{~mm}$ or greater are presented; those from smaller separations are naturally less accurate. Because the error of a wavelength measurement by this method lies entirely in the fractional order, it would appear desirable to hold this to a minimum and increase the integral order indefinitely. However, a limit is set by the failure of the cadmium red radiation to show sharp interference fringes beyond 400,000 waves. Even at retardations of 326,000 waves the cadmium fringes appear somewhat wide and indistinct, as shown in figure 4, and the fractional order cannot be found with the same accuracy as for ${ }_{80}^{198} \mathrm{Hg}$ lines.

TABLE 1. Preliminary values of ${ }_{80}^{198} \mathrm{Hg}$ wavelengths relative to $\mathrm{Cd} 6438.4696 \mathrm{~A}$ in normal air

\begin{tabular}{|c|c|c|c|c|c|c|c|c|c|c|c|c|}
\hline \multirow{2}{*}{$\begin{array}{l}\text { Whole } \\
\text { angstroms }\end{array}$} & \multicolumn{12}{|c|}{ Fractional angstroms with interferometer-plate separations } \\
\hline & $40 \mathrm{~mm}$ & $\begin{array}{l}\text { Ob- } \\
\text { serva- } \\
\text { tions }\end{array}$ & $50 \mathrm{~mm}$ & $\begin{array}{l}\text { Ob- } \\
\text { serva- } \\
\text { tions }\end{array}$ & $67 \mathrm{~mm}$ & $\begin{array}{l}\text { Ob- } \\
\text { serva- } \\
\text { tions }\end{array}$ & $90 \mathrm{~mm}$ & $\begin{array}{l}\text { Ob- } \\
\text { serva- } \\
\text { tions }\end{array}$ & $105 \mathrm{~mm}$ & $\begin{array}{l}\mathrm{Ob}- \\
\text { serva- } \\
\text { tions }\end{array}$ & Means & $\begin{array}{l}\text { Total } \\
\text { Observa- } \\
\text { tions }\end{array}$ \\
\hline $5,790 \ldots$ & 0.6628 & 10 & 0.6627 & 10 & 0.6628 & 6 & 0.6627 & 2 & 0.6627 & 1 & 0.6627 & 29 \\
\hline $5,769 \ldots$ & .5982 & 10 & .5983 & 10 & .5985 & 6 & .5985 & 2 & .5983 & 1 & .5984 & 29 \\
\hline $5,460 \ldots$ & .7532 & 9 & .7532 & 10 & .7533 & 6 & .7532 & 3 & .7532 & 3 & .7532 & 31 \\
\hline $4,916 \ldots$ & .0697 & 5 & .0699 & 2 & -.... & ..... & ...... & ..... & -.... & -.... & .0698 & 7 \\
\hline $4,358 \ldots$ & .3377 & 9 & .3377 & 8 & .3376 & 6 & .3377 & 3 & .3375 & 3 & .3377 & 29 \\
\hline $4,347 \ldots$ & .4959 & 7 & .4961 & 5 & -..... & .... & -.... & - & -.... & .... & .4960 & 12 \\
\hline $4,339 \ldots$ & .2248 & 5 & .2252 & 2 & -..... & -.... & - & -... & -.... & -... & .2250 & 7 \\
\hline $4,077 \ldots$ & .8383 & 7 & .8382 & 8 & .8381 & 4 & - & .... & -.... & -... & .8382 & 19 \\
\hline $4,046 \ldots$ & .5718 & 9 & .5717 & 10 & .5717 & 6 & .5716 & 3 & .5715 & 2 & .5717 & 30 \\
\hline
\end{tabular}

TABLE 2. Preliminary values of ${ }_{80}^{198} \mathrm{Hg}$ wavelengths relative to $\mathrm{Cd} 6438.4696 \mathrm{~A}$ in normal air

\begin{tabular}{|c|c|c|c|c|c|c|c|c|}
\hline \multirow[b]{2}{*}{$\begin{array}{l}\text { Whole } \\
\text { angstroms } \\
\text { e }\end{array}$} & \multicolumn{8}{|c|}{ Fractional angstroms with interferometer-plate separations } \\
\hline & $\begin{array}{c}50 \\
\mathrm{~mm}\end{array}$ & $\begin{array}{l}\text { Ob- } \\
\text { ser- } \\
\text { va- } \\
\text { tions }\end{array}$ & $\begin{array}{c}67 \\
\mathrm{~mm}\end{array}$ & $\begin{array}{l}\text { Ob- } \\
\text { ser- } \\
\text { va- } \\
\text { tions }\end{array}$ & $\begin{array}{c}90 \\
\mathrm{~mm}\end{array}$ & $\begin{array}{l}\text { Ob- } \\
\text { ser- } \\
\text { va- } \\
\text { tions }\end{array}$ & Means & $\begin{array}{l}\text { Total } \\
\text { obser- } \\
\text { vations }\end{array}$ \\
\hline $5,790 \ldots$ & 0. 6628 & 18 & 0.6627 & 15 & 0.6626 & 12 & 0.6627 & 45 \\
\hline $5,769 \ldots$ & .5985 & 18 & .5984 & 15 & .5984 & 12 & .5984 & 45 \\
\hline 5,460 & .7532 & 20 & .7533 & 15 & .7531 & 12 & .7532 & 47 \\
\hline $4,358 \ldots$ & .3378 & 20 & .3376 & 15 & .3377 & 12 & .3377 & 47 \\
\hline $4,077 \ldots$ & .8383 & 2 & -....... & $\ldots$ & - & ...... & .8383 & 2 \\
\hline 4,046 & .5718 & 20 & .5715 & 15 & .5717 & 12 & .5717 & 47 \\
\hline
\end{tabular}

Preliminary measurements for the wavelengths of green and yellow lines of ${ }_{80}^{198} \mathrm{Hg}$ have been reported [25] from the National Physical Laboratory and from the International Bureau of Weights and Measures, as follows:

NPL: 5460.7531, 5769.5985, 5790.6628 A. IBWM: $5460.7533, \quad 5769.5986, \quad 5790.6630 \mathrm{~A}$.

In addition to the ${ }_{80}^{198} \mathrm{Hg}$ wavelengths presented in tables 1 and 2, we have measured the wavelength of the only argon line recorded on our interference spectrograms; the average of 35 values obtained from plate separations of $40,50,67,90$, or $105 \mathrm{~mm}$ is $6965.4307 \mathrm{~A}$. 

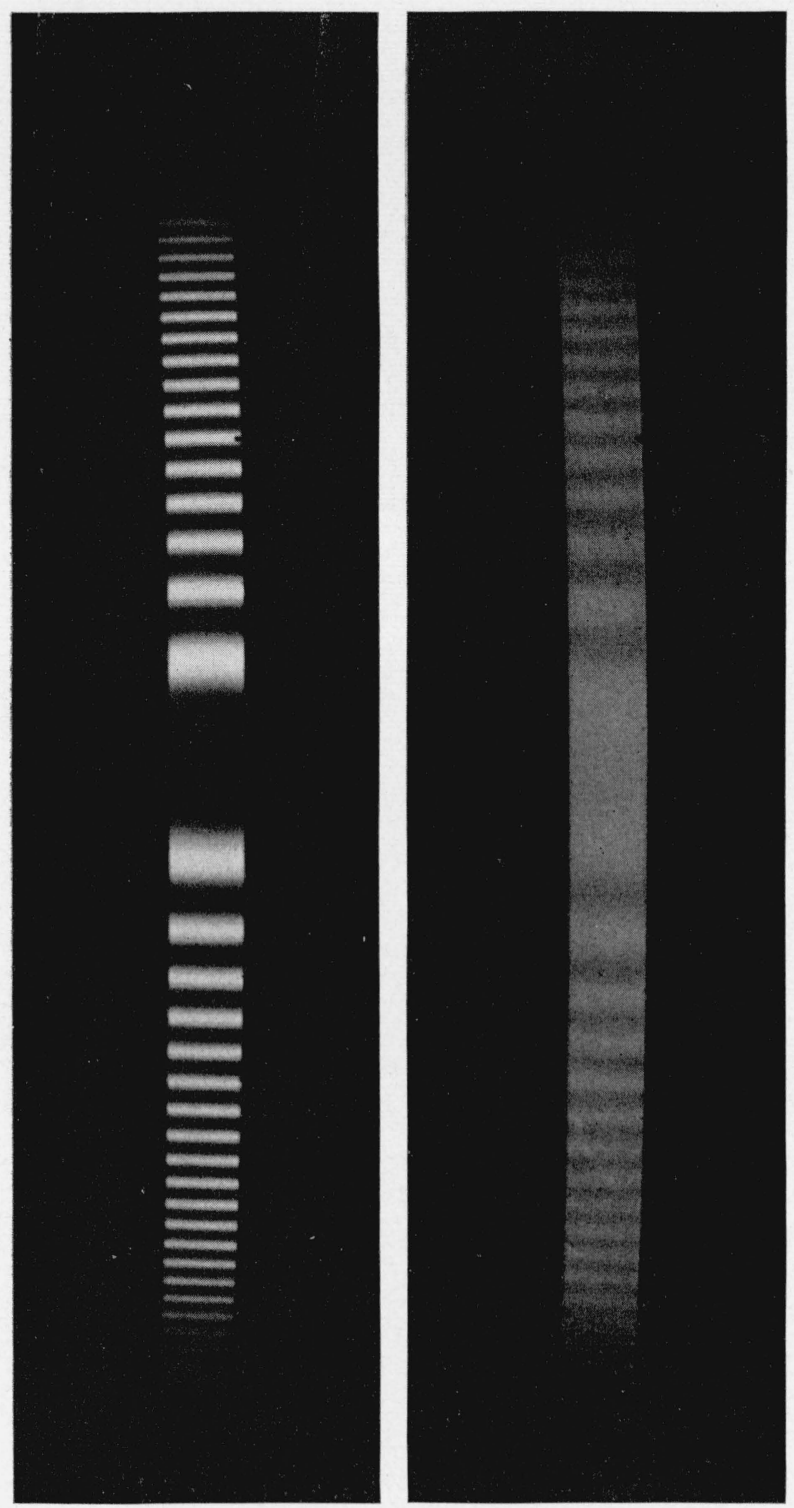

Figure 4. Fabry-Perot interference fringes with total retardation of $210 \mathrm{~mm}$ to compare sharpness of ${ }_{80}^{198} \mathrm{Hg}$ and Cd lines.

\section{References}

[1] A. A. Michelson and E. W. Morley, Am. J. Sci. 38, 181 (1889).

[2] A. A. Michelson, Phil. Mag. 34, 280 (1892).

[3] F. W. Aston, Mass spectra and isotopes (Longmans, Green \& Co., New York, N. Y. 1942).

[4] H. Schüler and J. E. Keyston, Z. Physik. 72, 430 (1931).

[5] E. Fermi, E. Amaldi, O. D’Agostino, F. Rasetti, and E. Segre, Proc. Roy. Soc. 146 A, 484 (1934).

[6] J. H. Wiens and L. W. Alvarez, Phys. Rev. 58, 1005 (1940).

[7] J. H. Wiens, Phys. Rev. 70, 910 (1946).

[8] W. F. Meggers, Rev. Modern Phys. 14, 59 (1942).

[9] W. F. Meggers, J. Opt. Soc. Am. 38, 7 (1948).

[10] W. F. Meggers, Sci. Monthly 68, 3 (1949).

[11] P. Bradt and F. L. Mohler, Phys. Rev. 73, 925L (1948).

[12] K. G. Kessler, Phys. Rev. 77, 559 (1950).

[13] C. P. Keim, Phys. Rev. z6, 1270L (1949).

[14] E. Jacobsen and G. R. Harrison, J. Opt. Soc. Am. 39, No. 12 (1949).

[15] H. Buisson and C. Fabry, J. Phys. (4) 7, 169 (1908); C. Fabry and H. Buisson, Astrophys. J. 28, 169 (1908).

[16] W. F. Meggers and C. J. Humphreys, J. Research NBS 18, 543 (1937) RP992.

[17] K. W. Meissner, J. Opt. Soc. Am. 31, 409 (1941).

[18] F. H. Rolt and H. Barrell, Proc. Roy. Soc. A122, 122 (1929).

[19] F. G. Gauss, Tafeln für Maschinenrechnen (Konrad Wittwer, Stuttgart, 1912).

[20] W. F. Meggers and C. G. Peters, BS Sci. Pap. 14, 724 (1918) S327.

[21] W. F. Meggers, BS Sci. Pap. 12, 199 (1915) S251.

[22] J. W. Marden, N. C. Beese and G. Meister, J. Opt. Soc. Am. 30, 184 (1940).

[23] Procès-Verbaux Comité Int. Poids et Mesures (2) 12, 67 (1927).

[24] Trans. Int. Astron. Union 6, 79 (1938).

[25] A. Pérard and J. Terrien, Compt. rend. 228, 964 (1949).

Washington, December 18, 1949. 